\title{
From initiatives to employee-driven innovations
}

\section{Haapasaari, Arja}

2018

Haapasaari , A , Engestrom , Y \& Kerosuo , H 2018 , ' From initiatives to employee-driven

innovations ' , European Journal of Innovation Management , vol. 21 , no. 2 , pp. 206-226 . https://doi.org/10.1108/E

http://hdl.handle.net/10138/237280

https://doi.org/10.1108/EJIM-09-2016-0085

submittedVersion

Downloaded from Helda, University of Helsinki institutional repository.

This is an electronic reprint of the original article.

This reprint may differ from the original in pagination and typographic detail.

Please cite the original version. 
European Journal of Innovation Management, https://doi.org/10.1108/EJIM-09-2016-0085

From initiatives to employee-driven innovations

Arja Haapasaari, Yrjö Engeström and Hannele Kerosuo

\begin{abstract}
Purpose - The purpose of this paper is to examine the generation of innovations by employees and the creation of initiative paths, and to discover which factors contribute to the implementation of an initiative.
\end{abstract}

Design/methodology/approach - Based on longitudinal qualitative research, the study explores the profiles of initiative paths and the types of innovations and relationships among the generated innovations.

Findings - It was found that, to become an innovation, an initiative followed different paths along which the processing and outcomes varied, as did the time needed for experimentation. The creation of initiative paths required the transformative agency of the actors involved. Power relations had an impact on the generation of initiatives and implementation of innovations.

Originality/value - Innovations research has concentrated on the generation of ideas generation and the implementation of innovations. This study focuses on the process path along which ideas become innovations and on the role of power relations in the innovations process.

Keywords Innovation, Activity theory, Power relations, Transformative agency

\title{
1 Introduction
}

Innovations research over the years has concentrated on both ends of an innovation process, namely ideas generation and ideas realisation. Ideas generation and creativity require the innovative behaviour of employees. Several studies have focused on this starting point of the process (Amabile, 1996; Mumford, 2000; Ohly et al., 2006). Innovations implementation has also been explored in the research literature: what are the key factors that facilitate the successful implementation of an innovation (Klein and Knight, 2005); what is the role of the management in innovations implementation (De Jong and Den Hartog, 2007; Michaelis et al., 2010), and what is the impact of the organisational climate (Baer and Frese, 2003). Thus, innovations research has overlooked a crucial part of the innovations process - how initiatives turn to innovations. This study focuses on the grey area that has often been overlooked. 
The generation of innovations has traditionally been regarded as needing particular skills and thus belonging to a special R\&D unit. However, resources for initiating innovations are scattered throughout an organisation. Total quality management, continuous improvement and suggestion schemes have been used as tools in involving employees in development programmes in organisations. However, without integration with strategic objectives, paying attention to employee diversity and motivation to submit suggestions, the true potential of suggestion systems has not been realised (Shapiro, 2000; Buech et al., 2010). Research on employee-driven activity and innovation has increased in recent years (Ellström, 2010; Høyrup, 2010; Kesting and Ulhøi, 2010). In this study we examine the initiatives made by ordinary workers in a production unit. The agency of the workers (Engeström, 2011; Vänninen et al., 2015; Haapasaari et al., 2016), especially their ability to search for alternative options, find a solution to inefficient activity and create the most promising innovation path, is critical (Garud and Karnoe, 2001). The concepts of path dependence and path creation have been used in different levels of analysis. Most previous research has focused on technological trajectories (David, 1985; Arthur, 1989) but the focus has shifted more recently to micro-level analysis of organisational paths (Gruber, 2010; Thrane et al., 2010). This study contributes to the literature on employee-driven innovation, agency and path creation by focusing on the micro-level analysis of organisational paths, the agency and innovative capacity of the workers.

The data of this study are drawn from a Change Laboratory (CL) intervention (Engeström, 2007; Virkkunen and Newnham, 2013) conducted in a production unit of a large Finnish company. The initiatives and innovations that were part of the change processes of the work activity were activated by a longitudinal intervention and follow-up period. The aim of the intervention was to enable workers to participate in work development and the creation and development of innovations. Thus, the contribution of this study is to bring together the literature on interventions and employee-driven innovations.

Furthermore, this study contributes to innovations research by examining innovations on different levels. A typical division of innovations from incremental to radical is valuable (Meeus and Edquist, 2006), however, it is too broad and dichotomist. A deeper and finer examination highlights the multifaceted nature of innovations. Additionally, the dynamic relationships of innovations are highlighted in this research. An innovation can comprise several smaller innovations which, by blending in with each other, construct a larger innovation.

Employee-driven activity does not live alone. It is influenced by the activity of the management, colleagues in the network and the wider community. Thus, in this study we ask, on whose terms 
were the initiatives presented, and how was the activity developed? Besides the employees, initiatives may come from above - presented and instructed by the management - or from the side, dictated by the colleagues in the wider network (Swan and Scarbrough, 2005). However, employees can take the mandate and influence the implementation of initiatives. The implementation of an initiative is a critical phase in an innovation process and path creation. By using power, implementation can be either promoted or prevented. The aim of this study is to expand our knowledge of power relations (Hardy and Clegg, 1996; Blackler et al., 1999) and the role of power in promoting and preventing the implementation of an initiative.

The overall research question of the study is: How are initiatives turned into innovations, developed and implemented, or terminated? The more specific research questions are: (1) Do initiatives become paths, and if they do, what kind of profiles of initiative paths are there to be found? (2) What types of innovations and what kinds of dynamic relationships are found within initiatives? (3) Which factors contribute to, or prevent the implementation of an initiative, and especially, what is the role of power relations? (4) To what extent are initiatives and innovations sustainably implemented?

In the following sections, we first discuss the theoretical concepts of innovation, path creation, agency, and power relations. We then describe the setting and data collection, as well as the methods of analysis. After that, we present our findings concerning each research question. Finally, we discuss the findings in relation to relevant literature and draw conclusions.

\section{Innovation, path creation and power relations in work organisations}

Innovation is a multi-dimensional concept that has been approached from several perspectives. Different definitions exist in the literature (for example, West and Farr, 1990, p. 9; Klein and Sorra, 1996, p. 1057; LePine and Van Dyne, 1998, p. 865). Central to these definitions is that an innovation can be an idea, a process, a product or a procedure, that challenges former practices, and leads to better accomplishment of goals. Furthermore, an innovation is new to its developers and potential users, regardless of whether it has been invented and implemented in other organisations. Thus, innovation is often examined in a local context where it is developed and processed. We apply this broad definition of an innovation to this study. According to Meeus and Edquist (2006), innovations can be small continuous changes in an activity or major discoveries or breakthroughs in a particular field. Incremental changes focus on modifications and improvements in products, processes or current practices. Radical innovations can bring earth-moving changes to ways of 
acting and possibly lead to massive shifts in technology and the creation of new businesses. As Fenwick (2003) points out, opportunities for innovative initiatives appear in everyday problemsolving situations.

Researchers (Rank et al., 2004; Holman et al., 2012) have described innovation as a process that starts with the generation of an idea, proceeding to the promotion of an idea aiming at the realisation of that idea. According to Holman et al. (2012) ideas generation includes the production of truly new ideas, as well as ideas that are new in a local context, even though they may have been adopted from elsewhere. Ideas promotion means presenting initiatives to others and persuading them to accept and adopt those ideas. Ideas realisation belongs to the implementation phase of the innovation process. Implementation is the critical phase when the use of an innovation becomes routine in an organisation. Klein and Knight (2005) note that innovations are often adopted by organisations but the successful implementation of them fails.

Innovations can be examined as closed categories or open processes. A closed category is a clearly defined innovation. It can be a new product or service. From the process perspective, an innovation is continuous and open. As Von Hippel and Tyre suggest 'innovation may best be seen as a continuous process, with particular product embodiments simply being arbitrary points along the way.' (Von Hippel and Tyre, 1995, p.12). The starting point of this study is particularly the processoriented view of innovations. This viewpoint implies that the line between an initiative and an innovation is flexible. Thus in this study we follow the paths that may lead from initiatives to clearly defined innovations, or that develop in that direction.

Innovations processes are extremely complex and rarely illustrated in detail in scientific literature. Van de Ven and Poole (1990) introduce methods to study the process of innovations development, how and why innovations emerge, develop and are implemented, or terminated. They state that different innovations follow different paths.

The concept of path dependence, which relates former decisions to future events and courses of action, is central to understanding transformations. The dark side of path dependence is that inefficiencies and sub-optimal solutions may become locked in (David, 1985; Arthur, 1989). The examination of factors that bring about inflexibility and lock-in situations in organisational paths has been at the forefront of research. Scholars have focused less on the initial conditions and origins of organisational paths (van Driel and Dolfsma, 2009; Schreyögg and Sydow, 2011) and actors' activity in path creation (Garud and Karnoe, 2001; Stack and Gartland, 2003; Gruber, 2010). 
In introducing the concept of path creation, Garud and Karnoe $(2001$; 2003) emphasised the embedded agency of actors in the creation of new paths. Actors become involved with the emerging path that they try to shape in real time. Reciprocally, the path begins to shape the actors over time. Garud and Karnoe (2003) highlight the collective approach to agency, as development efforts require multiple actors. Thus, according to Garud and Karnoe, agency is distributed, embedded and varies by paths. However, to bring about a change in activity, the transformative agency of the actors is required.

Transformative agency is a key concept in activity theory. Virkkunen $(2006,49)$ defines transformative agency as 'breaking away from the given frame of action and taking the initiative to transform it'. According to Engeström (2011), transformative agency includes the actions of questioning the status quo and the search for new possibilities. Although initiated by individuals, transformative agency is collectively produced and maintained.

Garcia and Calantone (2002) discuss several innovation typologies. Researchers in the field, they point out, most often categorise innovations as either radical or incremental. Within activity theory, Engeström (1995) has examined the production of innovations and identified three main types of innovations: (1) solution, (2) process and (3) systems innovation. This categorisation arises from our theoretical framework. Solution innovation generates a solution to a problem that can manifest, for example, as a new tool, a new rule or a new form of distribution of work in an organisation. The aim of process innovation is to reorganise or manage more effectively a certain work process. Here the system relates to the activity system of the actors involved. The activity system comprises elements central to a certain activity, the subjects, the object involving the motive and purpose of the activity and the tools needed for the activity, regulating rules, the community the subjects belong to and division of labour. In systems innovation, the principles of the activity system are questioned and reconstructed. A new model or a vision consisting of several components is built up step-by-step. The three types of innovations are depicted in an activity system model in Figure 1. 
Figure 1. The three innovation types

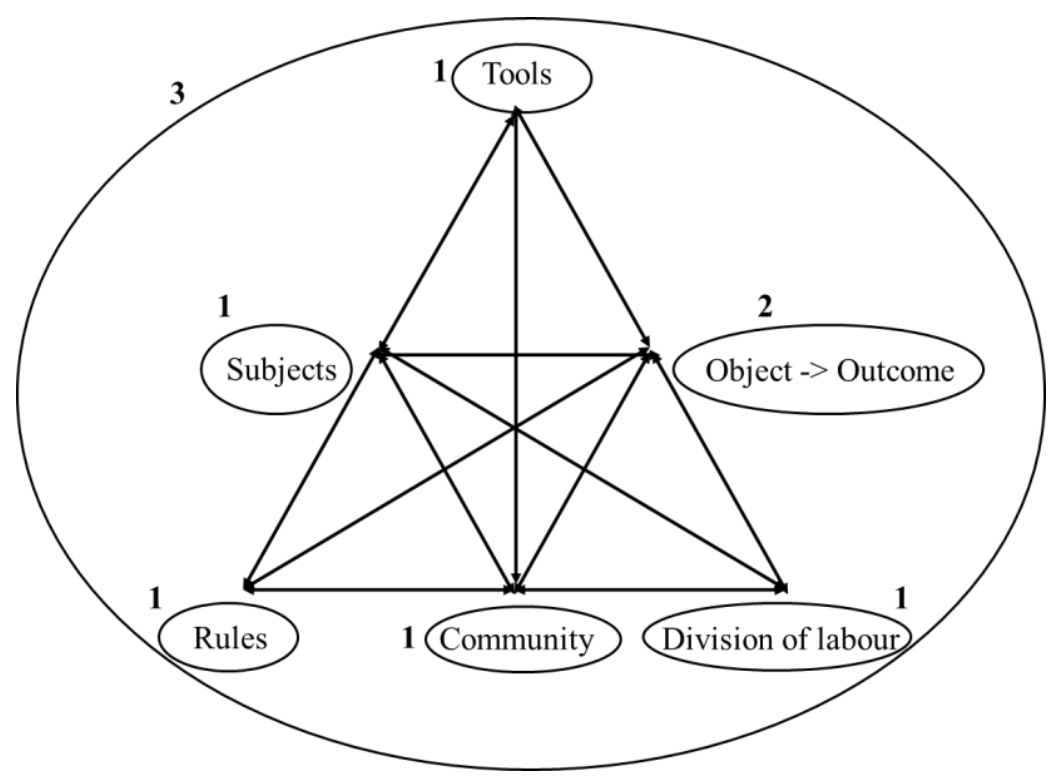

The generation of innovations has traditionally been regarded as belonging to an R\&D or a special unit in an organisation. Ordinary employees often participate in the development and initiate innovations through an initiative box. However, an organisation cannot afford to ignore the tacit knowledge (Nonaka, 1994) and the innovative resources of ordinary employees. Employee-driven innovations research focuses on innovative practices in organisations (Høyrup, 2010; Kesting and Ulhøi, 2010). We state that participation in work development requires methods and forums to engage employees. The Change Laboratory (CL) is an intervention method developed within activity theory that involves the participants in work development and supports their transformative agency.

According to Hardy and Clegg (1996), in order to learn about power, researchers should examine how certain voices in an organisation and social situations are either heard, or silenced. Hardy (1996) identifies three dimensions of power which are based on resources, processes and meaning. Resource power means that actors who control resources have the power over the others. Related, for example, to knowledge, the groups that do not have knowledge are outflanked. The process dimension of power is embedded in the organisational decision-making processes. Hardy and Clegg (1996) state that, the more powerful groups decide which issues are taken onto the agenda, and thus determine the outcomes. By managing shared meanings, the more powerful groups shape the perceptions within an organisation (Hardy 1996). In their study on networked innovation processes, Swan and Scarbrough (2005) highlight the importance of process and meaning power (power to) rather than resource power (power over) as the critical factor in innovation processes. Moreover, 
Hardy and Clegg (1996) point out that a characteristic of power is discretion, which includes the possibility of resistance. Thus, power and resistance comprise a system of power relations.

Contrary to Hardy and Clegg (1996), Blackler and McDonald (2000) approach power not only as a medium for, but also as an ongoing product of, collective activity. In their study on the management of innovation, Blackler et al (1999) show that solutions to problems and innovations may also be developed from bottom-up as well as from top-down. Accordingly, they suggest that forums and rules for dialogue in an organisation are needed to promote the articulation of multiple perspectives.

\section{The setting and the data collection}

The site of this research is a work unit called Solution Services at one of the sorting centres of the Posti Corporation in Finland, where we conducted a Change Laboratory (CL) intervention during the winter of 2010-11. Posti is a service provider of postal, logistics and e-commerce services, owned by the state of Finland. The activity system of the work unit comprised eight blue-collar employees, four senior and four junior members. Four of the employees were female and four male. The names used in this paper have been changed to protect their identities. The role of the employees was to handle deviations that might occur during the sorting process at the sorting centre or in other phases of the delivery process within the company. The employees did not engage in trouble-shooting activity individually (Orr, 1996) but collectively. The work was carried out by utilising several traditional and information technology tools. The work unit was part of a community consisting of other sorting centres and customer service departments in the company.

$\mathrm{CL}$ is an intervention method that supports the formation of the transformative agency of the participants (Engeström, 2007; Virkkunen and Newnham, 2013). The CL intervention consisted of nine sessions. The first session was held on November 9, 2010 and the last on February 1, 2011. The CL aimed to help workers and the supervisor Tom to develop work practices, competences and co-operation, through incremental changes and improvements. After the CL, there was a follow-up period, from February, 2011, to March, 2012. During the spring of 2011 four follow-up meetings were organised. In the autumn of 2011 the members of the work unit started to have team meetings once a week, which were led by the employees themselves. The team-meeting practice was an innovation initiated by the employees during the follow-up period. The researcher and the first author of this paper participated in 10 team meetings. The researcher's role was no longer as an interventionist, but required her to follow and document how the transformative agency of the CL 
participants and the status of the innovations were sustained. They selected meetings that covered the entire follow-up period, including the beginning, the middle phase and the end.

The researcher also interviewed CL participants during the summer of 2013, over a year after the follow-up period had ended. Six participants were interviewed, as two of them could not be reached. Tom, who no longer worked at the company, was interviewed in December, 2013.

The data analysed in this paper consist of nine CL sessions, four follow-up sessions and 10 team meetings in which the researcher participated. The CL sessions were both video and audiorecorded. The follow-up and team meetings were audio-recorded, with the data transcribed verbatim. The transcripts consist of speaking turns expressed by the participants. The amount of turns is 17,752 . The interviews were audio-recorded. They were not transcribed verbatim, but speaking turns containing references to innovations initiated during the CL and the follow-up period were examined in order to check the status of these innovations.

\section{Methods of analysis}

In this study, we have applied three different classification methods to answer the four research questions. The coding categories for each method are summarised in Table 1. The categories for the research questions 1 and 4 are presented in regular font, for the second in bold, and for the third in italics.

\begin{tabular}{llll}
\hline $\begin{array}{l}\text { Research question } \\
\text { 1: Profiles of } \\
\text { initiative paths }\end{array}$ & $\begin{array}{l}\text { Research question } \\
\text { 2: Types of } \\
\text { innovations }\end{array}$ & $\begin{array}{l}\text { Research question 3: Power } \\
\text { relations }\end{array}$ & $\begin{array}{l}\text { Research question 4: } \\
\text { Profiles of initiative } \\
\text { paths }\end{array}$ \\
\hline $\begin{array}{llll}\text { Implemented } \\
\text { Lost momentum }\end{array}$ & $\begin{array}{l}\text { Solution innovation } \\
\text { Process innovation }\end{array}$ & $\begin{array}{l}\text { Directive power top-down } \\
\text { Enablement top-down }\end{array}$ & $\begin{array}{l}\text { Implemented } \\
\text { Implement momentum }\end{array}$ \\
$\begin{array}{l}\text { Changed } \\
\text { Remained open }\end{array}$ & Systems innovation & No decision top-down & Terminated \\
Commitment bottom-up & Implemented once \\
\hline
\end{tabular}

Table 1 . The coding categories

We have applied methodological guidelines introduced by Van de Ven and Poole (1990) to examine the development of innovations in longitudinal qualitative data. The speaking turns were carefully examined and turns containing an initiative were selected as a starting point for the analysis. The starting point contained information about the date of the meeting, the initiator and actors involved, the presented initiative or the solution to the problem, and the theme relating to the 
problem. Incidents related to the initiatives in the following meetings were examined and information about the date of the meeting, actors involved, description of the incident and outcomes were logged in a file.

Every incident related to an initiative occurred in a different meeting. Thus, every meeting where the initiative was discussed formed a link in a chain on the initiative path. The initiative path could consist of only one meeting or it could extend over a period of several meetings. In longitudinal qualitative research such as this, and especially because the researcher was not present at every meeting, it is important to notice, as Van de Ven and Poole (1990) highlight, that the incidents represent a sample of indicators of what happened along the initiative path.

As Van de Ven and Poole (1990) suggest, the innovation process can be viewed as a temporal sequence of separate stages. The idea of a phase analysis is 'to identify and compare developmental phases in the temporal sequence of data' (329). We applied this idea so that we followed what happened to the initiatives on the paths over time. Most of the initiatives were either implemented, or terminated. However, some of the initiatives were experimented with and developed but they lost momentum along the path. A couple of initiatives remained open as there was no decision or information about the implementation in the data. Thus, we identified four main categories of initiative paths, which we coded as follows: implemented, terminated, lost momentum and remained open.

Our second research question asks: what types of innovations are found within initiatives? A typical way to analyse innovations is to divide them into either radical or incremental. As the initiatives in our data were not especially radical, a finer categorisation of initiatives was needed. Thus, we categorised initiatives into three types, as identified by Engeström (1995): solution, process and systems innovation. It was important to decide to which theme of discussion the initiative belonged in order to discover whether it was linked to a certain work process (for example, to the handling of undeliverable goods). The coding categories for the themes were developed on the basis of the empirical data. To reveal whether there were system-level innovations in the data, we used the concept of the activity system. Thus, by categorising the initiatives to a theme and further to a work process or an element of the activity system of the work unit, we could examine the innovation types.

Our third research question asks: which factors contribute to, or prevent the implementation of an initiative, and especially, what is the role of power relations? According to Hardy and Clegg (1996), the system of power relations comprises the 'power to', and 'power over', as well as 'resistance to 
power'. 'Power to' highlights the possibilities of influencing processes and shared meanings in an organisation. 'Power over' emphasises the ownership of resources. Moreover, the initiatives for solutions to problems and innovations may come from top-down and bottom-up in an organisation (Blackler et al., 1999). Thus, for the analysis of power relations we draw up four fields, illustrated in Figure 2. The horizontal axis consists of the dimensions of 'power to', 'power over' and 'resistance to power', and the vertical axis comprises the dimensions from top-down and from bottom-up.

Figure 2. The four fields of power relations

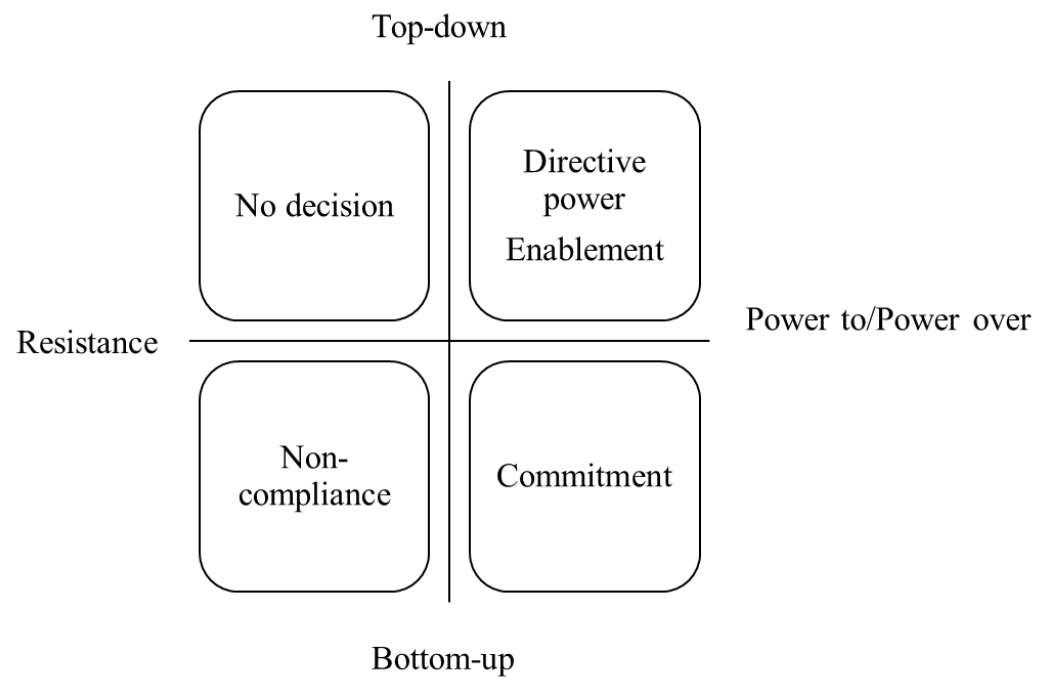

The contents of each of the four fields come from empirical data. Directive power from the topdown is a legitimate form of power in an organisation. Besides the formal hierarchical power, the supervisor can enable employees to develop and experiment with initiatives. The employees, in turn, can use power by promoting and committing to an initiative. Resistance to power is manifested in actions of non-compliance or not making any decisions. The actions of power and resistance in our data are interpreted from the viewpoint of transformative agency.

Our fourth research question asks: to what extent are the initiatives and innovations sustainably implemented? To answer this question we used the same categorisation as that used for our first research question.

The coding categories for the first and the fourth, and the third research questions were developed on the basis of iterative reading of the empirical data. For the second research question the classification of innovation types identified by Engeström (1995) was utilised. No computer programme was used for the analyses. The coding was done independently by members of the CL 
research team. Disagreements among coders were collectively discussed and resolved with the help of researchers not involved in the intervention.

In the following sections we present both the quantitative and qualitative findings of our study. First, in section 5, we give a quantitative overview of the profiles of initiative paths. Then, in section 6, we examine qualitatively the types of generated initiatives and their relationships. In section 7 we combine quantitative and qualitative analyses of the factors that contributed to the implementation of an initiative. In section 8 we present a quantitative analysis of the sustainability of the implemented initiatives.

\section{Profiles of initiative paths}

Our first research question is: Do the initiatives become paths, and if so, what kind of profiles of initiative paths are there to be found? We will first discuss the starting point of a path, the initiator of an initiative, and the outcomes. We then examine the profiles of the paths. During the CL (9.11.2010-1.2.2011) and the follow-up period (2.2.2011-15.3.2012) altogether 105 initiatives were presented.

\subsection{Points of beginning/initiation}

Initiatives and development ideas were often preceded by criticism. Employees criticised issues in an activity that hindered fluent working and where solutions needed to be developed. As Blackler $e t$ al (1999) state, work development requires joint forums for discussion where issues can be highlighted. The CL sessions and the joint meetings during the follow-up period were important forums, where employees had the opportunity to discuss and develop their work and work practices. In response to criticism, a solution to a problem was developed. In the case of some initiatives, employees had worked on a solution in smaller groups and presented it in the meeting. The supervisor Tom was also an active developer and presented initiatives and gave new instructions. Additionally, he communicated the initiatives from the management to the employees.

\subsection{The initiator and outcomes}

The initiatives were presented by the employees, Tom, the management, the colleagues in the network and the researcher (Table 2). Most of the initiatives were presented by the employees. They 
expressed transformative agency by questioning current work practices and searching for solutions to problems (Engeström, 2011; Haapasaari et al., 2016). The second was Tom and the third the researcher. Tom belongs to the management because of his role, but he can also be a change agent, who tries to develop the activity on his own initiative. Representatives of the management and the colleagues gave a few instructions and orders which Tom communicated to the employees. The development ideas presented by the researcher were responses to the challenges and problems expressed by the employees and colleagues in the network during interviews that took place before the CL.

\begin{tabular}{lrrrrrrr}
\hline & Implemented & $\begin{array}{c}\text { Lost } \\
\text { momentum }\end{array}$ & Terminated & $\begin{array}{c}\text { Implemented } \\
\text { once }\end{array}$ & Changed & Open & $\begin{array}{c}\text { Total } \\
(\%)\end{array}$ \\
\hline Employees & 34 & 6 & 13 & 0 & 1 & 6 & $60(57.1 \%)$ \\
Supervisor & 18 & 0 & 8 & 1 & 0 & 1 & $28(26.7 \%)$ \\
Management & 4 & 0 & 1 & 0 & 0 & 0 & $5(4.8 \%)$ \\
$\begin{array}{l}\text { Colleagues in } \\
\text { the wider }\end{array}$ & 1 & 0 & 0 & 0 & 0 & 1 & $2(1.9 \%)$ \\
network & & & & & & & \\
Researcher & 4 & 3 & 3 & 0 & 0 & 0 & $10(9.5 \%)$ \\
Total $(\%)$ & $61(58.1 \%)$ & $9(8.6 \%)$ & $25(23.8 \%)$ & $1(1 \%)$ & $1(1 \%)$ & $8(7.6 \%)$ & $105(100 \%)$ \\
\hline
\end{tabular}

Table 2. The initiator and outcomes of an initiative

As shown in Table 2, of the 105 initiatives, 61 were implemented. Twenty-five initiatives were terminated. Nine initiatives were tested out with the employees but not implemented. Eight initiatives were left open without a decision. One initiative was implemented just once, and the basic idea of one initiative changed along the path.

Of the 60 initiatives generated by the employees, 34 were implemented. The employees raised problems in day-to-day work issues and they developed the work collectively. The solutions that clearly improved work were thus implemented. Thirteen of the 60 initiatives were terminated. Six lost momentum and six were left open. One of the initiatives presented by the employees was changed as a result of joint development.

The initiatives generated by Tom included both development suggestions and instructions that the employees had to follow. Of the 28 initiatives presented by Tom, 18 were implemented. However, eight were terminated, one was implemented just once, and one was left open.

The management gave five instructions during the follow-up, of which four were implemented and one was left open. Even though the initiatives presented by the management were criticised, they 
were implemented. One initiative was not implemented due to the lack of human resources in the work unit at that time.

The colleagues in the network generated two initiatives, of which one was implemented and one was left open. The implemented initiative was related to co-operation. The way of working in the unit did not support the work of the colleagues and thus they presented an initiative to change the cooperation procedure.

Of the 10 initiatives presented by the researcher, four were implemented, three lost momentum and three were terminated. The employees tested out the presented ideas and implemented four that they felt improved work activity. The ones that lost momentum were experimented with and developed but were not deemed effective enough to warrant being implemented.

\subsection{Paths of implementation}

To follow the construction of paths it was essential to examine how the processing of initiatives proceeded in meetings and what happened to them along the way. The initiatives were processed in either one or several meetings. The initiative paths thus became short, medium or long. A short path means that the initiative was processed in one to two meetings. On a medium-long path the initiative was processed in three to five meetings. On a long path the initiative was processed in six or more meetings. As is visible in Table 3, the majority of the initiatives (72) followed a short path. There was almost an equal number of initiatives that developed a medium-long or a long path. Clearly, most of the initiatives were discussed and decisions made quite rapidly in one to two meetings. However, in some cases the issue could have been discussed before the meeting and only the beginning of the implementation confirmed in the meeting.

\begin{tabular}{lrrrrrrr}
\hline & Implemented & $\begin{array}{c}\text { Lost } \\
\text { momentum }\end{array}$ & Terminated & $\begin{array}{c}\text { Implemented } \\
\text { once }\end{array}$ & Changed & Open & $\begin{array}{c}\text { Total } \\
(\%)\end{array}$ \\
\hline Short (1-2) & 45 & 0 & 19 & 0 & 0 & 8 & $72(68.6 \%)$ \\
Medium (3-5) & 8 & 2 & 5 & 1 & 1 & 0 & $17(16.2 \%)$ \\
$\begin{array}{l}\text { Long (6 and } \\
\text { over) }\end{array}$ & 8 & 7 & 1 & 0 & 0 & 0 & $16(15.2 \%)$ \\
Total & 61 & 9 & 25 & 1 & 1 & 8 & $105(100 \%)$ \\
\hline
\end{tabular}

Table 3. The outcomes of initiative paths

Next we examined what happened to each path. On a short path initiatives were either implemented, or terminated. However, eight initiatives were left open. Thirty-three of the implemented initiatives 
were generated either by the employees, Tom or the researcher. The initiatives clearly improved work activity as decisions to implement were made promptly. Twelve initiatives manifested as instructions given by Tom, the management or the colleagues, which had to be followed and implemented.

Regarding the terminated initiatives, Tom's role became vital. If he did not regard an initiative important, or if in his opinion the initiative did not enhance ways of working, he used power not to promote it. Certainly, Tom was not responsible for the termination of all 19 initiatives. Three of the initiatives were not supported by the employees and were thus not implemented. The employees also used power in those cases and did not implement initiatives that did not help their work. The employees were responsible for those initiatives that remained open. For an initiative to have been implemented would have required actions on the part of the employees.

On a medium-long path, initiatives were mostly either implemented or terminated. Eight of the 17 initiatives were implemented, five were terminated and two lost momentum along the path. Table 4 shows that when initiatives were developed by the employees, they were mostly implemented. However, when the employees discussed further the initiatives these were not implemented. The reason for the five initiatives that were discussed further and terminated was that they were dependent on the decisions of the management. Regarding the initiative that was implemented once, and the initiative that was changed, Tom used his power to decide on the procedure.

\begin{tabular}{lrrrrrr}
\hline & Implemented & $\begin{array}{c}\text { Lost } \\
\text { momentum }\end{array}$ & Terminated & $\begin{array}{c}\text { Implemented } \\
\text { once }\end{array}$ & Changed & Total \\
\hline Medium & 8 & 1 & 0 & 1 & 0 & 10 \\
$\quad$ Developed & 0 & 1 & 5 & 0 & 1 & 7 \\
$\quad$ Discussed further & 5 & 5 & 0 & 0 & 0 & 10 \\
Long & 3 & 2 & 1 & 0 & 0 & 6 \\
$\quad$ Developed & 5 & & & & & \\
$\quad$ Discussed further & & & & & & \\
\hline
\end{tabular}

Table 4. The outcomes of initiatives on medium-long and long paths

On a long path, initiatives were either implemented or they lost momentum. Eight of the 16 initiatives were implemented and seven lost momentum. Only one was terminated. As can be seen in Table 4, when initiatives were developed the outcome was either implementation or losing momentum. A long path resulted when an initiative required thorough discussion. Losing momentum of the initiatives was due to an increased quantity of goods, a shortage of human resources and pressure on efficiency. The initiatives that were discussed further were also either implemented or they lost momentum. A long path resulted from the three initiatives that were 
discussed further and finally implemented either because of a lack of resources in the work unit, or prolonged decision-making by Tom. Losing momentum was due to the contradictory expectations of the employees or dependence on the decision of the management. The terminated initiative was also dependent on the decision of the management.

Additionally, we examined the distribution of the 105 initiatives between those that were presented in the CL and those presented during the follow-up period. The distribution was quite even - 54 in the CL and 51 during the follow-up. The length of the paths is shown in Figure 3.

Figure 3. The length of initiative paths

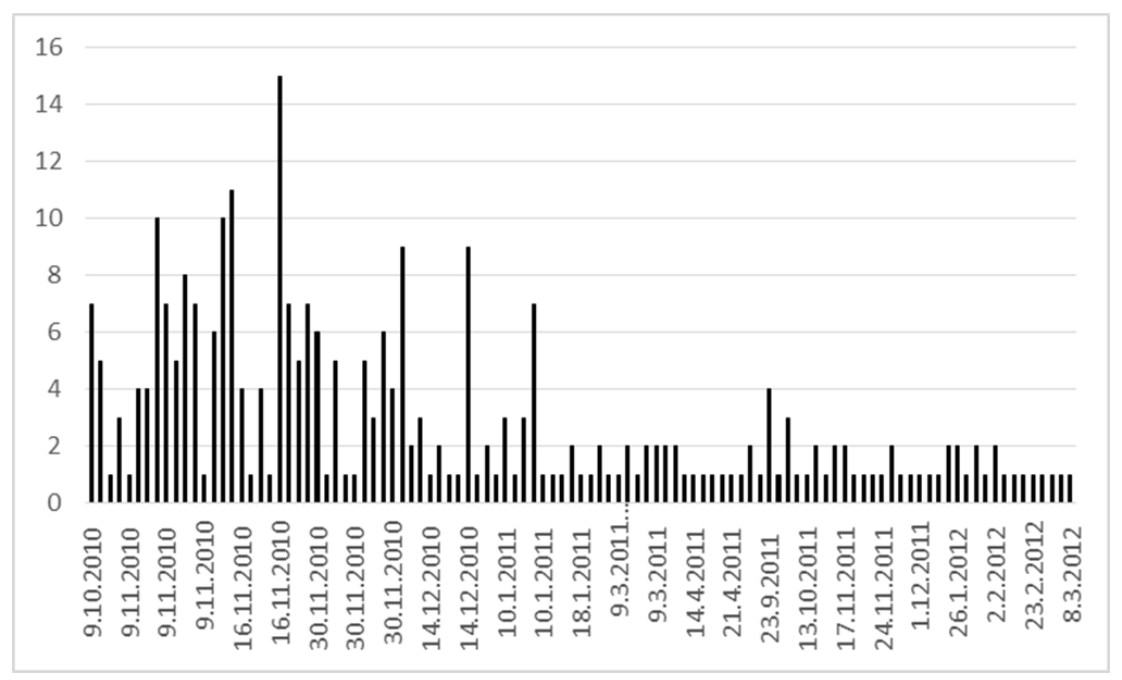

Most interesting is that the initiatives presented in the CL resulted in short, medium and long paths, but during the follow-up the paths were mainly short. In the CL the employees were provided with a special opportunity and time to discuss and find solutions to problems at work. The development and further discussion of these initiatives continued during the follow-up period. Tom was strongly committed to the CL. Thus, the CL method supported the development of work activity. During the follow-up the employees had team meetings where decisions on initiatives were made quickly and not developed or discussed further in the course of several meetings.

\section{Types of innovation and dynamic relationships among the initiatives}

We now turn to our second research question - what types of innovations and what kinds of dynamic relationships are found among the initiatives? Our analysis used three innovation types identified by Engeström (1995). Of the 105 initiatives produced during the CL intervention and 
follow-up period, 102 were solution initiatives and three were process initiatives. Additionally, several solution initiatives contributed to process development.

As the dominant types of initiatives were solution- and process-innovation types, we present examples of both. The first example describes a solution initiative generated by the employees that turned to an innovation and was implemented (innovation type 1 in Fig. 1). The initiative path was short. In the first CL session on November 9, 2010, the employees criticised the way that information was shared in the group. They said that not everyone was informed about the new practices. Peter suggested a new tool - a whiteboard - that could be used in the internal communication of the group. Tom committed himself to take action to find a whiteboard.

Excerpt 1 (November 9, 2010, turns 516-521)

Peter: How can we make the internal communication of our group flow better? There ought to be something... something like a whiteboard could be...

Lisa: It would be good.

Tom: We could write down unfinished duties there. Information for the following morning - what is missing, what has been unfinished.

Kate: We can have ideas which help us, help the fluency of our work.

Tom: I'll find a whiteboard for us.

Kate: We may have small ideas. It would be good to write them down on the whiteboard so that everyone knows about them.

In the case of three of the initiatives, the employees had already had the idea of developing the process from the beginning. Two of these initiatives followed a medium path, and one a long path. The initiatives were developed and tested out. One of them was implemented and two lost momentum. According to activity theory, processes are the object of the activity (see innovation type 2 in Fig. 1). For example, the handling of small-sized loose goods is one of the processes that the employees take care of.

The second example describes the development of the implemented process innovation type. In a CL session on November 16, 2010, the researcher highlighted a problem related to the handling of small-sized valuable loose goods. The employees were critical about how they were currently doing their work. In order to make the process flow more smoothly Kate suggested that they should enter the data every day in a blotter and use envelopes and baskets for storing the goods. Criticisms continued in the next CL session a week later, and Kate suggested that she could implement the 
new way of working that they agreed upon. The strong personal commitment and desire to change the old way of working shown by Kate enhanced the implementation of the initiative.

Excerpt 2 (November 16, 2010, turn 538)

Kate: Well, could we now agree that someone sets this in motion, the blotter and then the [organising of the items] ... Now we could count the items and enter [the amount] in the blotter and check that they are right there. And then we could label the envelopes, [writing what's inside them], and after that [organise them in the same way for] the whole week. In this way, the envelopes would be in order. We should agree that one of us starts this now... Sets this in motion now. I can be a volunteer. Or does someone else want to do that?

In the CL session on December 10, 2010, in spite of the criticisms, the employees concentrated on developing the new way of working. Kate reported on the actions she had taken and all the others expressed commitment to the new way of working. In the CL session on January 10, 2011, the employees reported that the new process was flowing well. Clearly, after developing the ideas for the process and the tools to be used, the employees had created a shared and clear understanding of the method of working. This example describes well the process-oriented aspect of innovations.

Initiatives presented in the CL and during the follow-up period were mainly solution innovation types of initiatives. The employees did not analyse their work activity from a broader perspective in order to consciously develop work processes. However, it is clear that some of the solution initiatives were aimed at developing processes. During the analysis we put initiatives into groups according to a theme or a process that they were connected to. Thus it was possible to discover that Tom and the employees developed work processes more or less consciously. Altogether there were five processes which were developed by initiating several solution initiatives: the follow-up of packages (five initiatives); the handling of small-sized loose goods (seven initiatives); the handling of large-sized loose goods (four initiatives); handling of undeliverable goods (five initiatives) and the processing of queries from the customer service department (ten initiatives). Every initiative aiming at process development formed its own path - either short, medium or long. The initiatives were either implemented, terminated, they lost momentum or were left open. This shows that process development comprised small components and thus it was not abstracted too far from the routine of the employees. Often, idealistically drawn processes are not actually adopted in practice. Instead, processes developed by the employees will be implemented and developed further, using small steps. 
Initiatives and innovations developed during the CL and the follow-up period comprised two clusters of system-level innovations related to the entire activity system (type of innovation 3 in Fig. 1). The first systems innovation concerned learning, the sharing of knowledge and co-operation in the work unit. The second systems innovation reached beyond the work unit, to co-operation and development of co-operation with the wider network.

In the beginning of the CL, the employees said that their work unit consisted of separate members with various kinds of knowledge and experience. Co-operation in the unit was complicated and there were problems in information sharing. Not everyone knew what had been agreed. The human resources were not sufficient for fluent working when workers were on leave. During the CL and the follow-up Tom and the employees found solutions to these problems and built a qualitative change, piece by piece, on the system level. The employees developed knowledge and competence in the group by sharing knowledge and tutoring each other. Examples of tools in knowledge sharing included solution diaries, useful links in work instructions to intranet, team meetings chaired by the employees and internal training. Co-operation and information sharing in the work unit was improved by creating joint rules for peace and tidiness in an open office, having joint meetings, creating a joint e-mail address and an e-mail box for the group, implementing a whiteboard for information sharing, and having a training day to focus on group dynamics. Knowledge and cooperation was also improved by implementing a new way of working - working in pairs. In order to solve the human resource problem, the employees and Tom developed task rotation to be more effective. Task rotation supported the organising of the work as well as learning and sharing of knowledge.

To enhance co-operation with the wider network, Tom and the employees developed and implemented several initiatives that contributed to the emergence of a second system-level innovation. The employees found that their work was not respected everywhere in the organisation and they felt demotivated. On the other hand they had a strong desire to develop the activity and serve as consultants to production workers and the wider network. As a solution to the lack of respect, Tom bought special waistcoats with the words 'Solution Services' written on the back. The waistcoats were an important symbol for the employees, as the supervisors also had the same kind of waistcoats. The ordinary production workers did not have such waistcoats. Additionally, Tom drew up a description of the activity of Solution Services in order to show the wider network how the activity was linked to other activities in the company. New meeting practices and the implementation of a collection of indicators created for the Solution Services supported systematic development of the activity. In meetings with the colleagues in the network the employees 
highlighted problems and co-developed the activity in the company. A joint disk drive, which held an Excel file for certain goods, as well as a list of large-sized loose goods, serve as examples of this co-development.

It is difficult to draw a clear line between an initiative and a potential innovation. When we highlight the requirement of novelty to the users, whether or not other organisations have used the technology or practice previously, and regard innovation as a closed category, we can find five solution innovations in the data (innovation type 1 in Fig. 1). This represents $4.7 \%$ of all the initiatives.

Three of the innovations were aimed at improving knowledge and information sharing in the unit. The whiteboard (see the example and Excerpt 1) and meetings chaired by the employees (see the example and Excerpt 3) were innovations initiated by the employees. The initiative paths were short as the decision to implement the initiative was made promptly. Writing solution diaries (see the example and Excerpt 5) was suggested by the researcher. It was a potential innovation which was tested out but lost momentum during the follow-up period.

To enhance knowledge of the work carried out in the unit and to develop and strengthen cooperation with the colleagues in the network, the researcher initiated a potential innovation regular meetings with the colleagues. The initiative path was long as the practice was developed in several co-operation meetings. The innovative practice was adopted but lost momentum during the follow-up.

To improve efficiency and support systematic development of the activity, the researcher initiated another potential innovation - the collection of indicators. It served as a tool for the employees and the management by showing where development was needed and where the employees had achieved their targets. Before implementation it was developed and tested out along a long initiative path.

Clearly, the innovations understood as closed categories and novel to the members of the work unit were solution innovation types. Of the five innovations, two were initiated by the employees. However, most of the initiatives were initiated by the employees. This indicates that the employees co-developed initiatives to solve work-related problems but did not produce as many totally new innovations. Thus in our study innovation may be seen as a continuous process along which innovative solutions were initiated. 


\section{Factors contributing to the implementation of an initiative}

In this chapter we focus on our third research question and discuss, with three examples from the data, which factors supported the implementation of an initiative and which led to a situation where an initiative was terminated. The role of power relations is a focus of our analysis. The four fields in Figure 4 show the number of initiatives in which the factor in question influenced implementation or termination.

Figure 4. The four fields of power relations

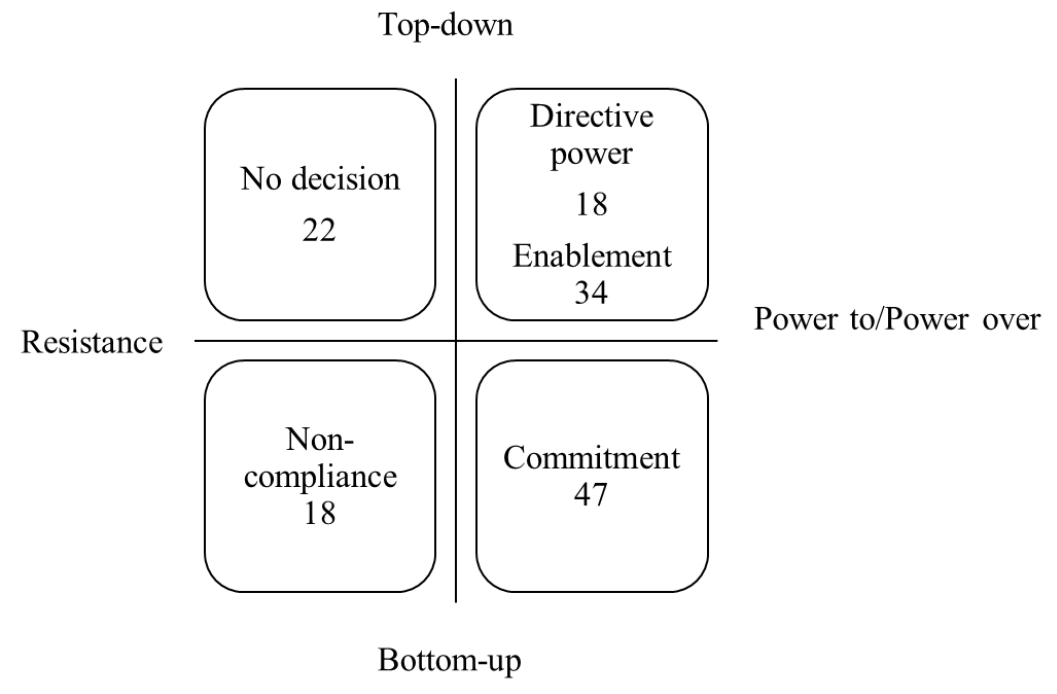

The management and the supervisor are owners of directive power and, based on this power, dictate how an activity shall be carried out. The management, as well as the supervisor Tom, used directive power to promote the implementation of an initiative or an instruction. Altogether there were 18 initiatives or instructions in which directive power was used. These initiatives formed mostly short paths, and only two followed a medium-long path.

Besides directive power, Tom used power to enable the employees to experiment with and develop initiatives. This facilitation supported experimentation, but did not necessarily secure implementation. In the case of 34 initiatives the enablement played a role. These initiatives formed mainly medium-long and long paths. With regard to the short paths, the initiatives had been developed before the meetings. The following example describes how the facilitation shown by Tom and co-development and commitment of the employees in promoting the initiative, advanced the implementation.

In the follow-up meeting on September 23, 2011, the employees criticised the way of sharing information in the group and complained that team meetings chaired by the supervisor had not been 
organised for a long time. They said that the meetings were essential for information sharing, as well as participation in decision-making and work development. Development of the idea started from the suggestion made by Lisa.

Excerpt 3 (September 23, 2011, turns 953-956)

Lisa: Could we have a team meeting, for example, every second Friday at $2 \mathrm{pm}$ so that people on the evening shift can participate?

Tom: We can put it [the meeting] into their shift so that their working day ends earlier. It's just a matter of organising.

Lisa: Yes. Every now and then everyone says that we should have a team meeting.

The idea of the team meeting was supported by the other participants and developed further during this meeting as well as at the following meeting on October 13, 2011. As a result of the discussions, Tom and the employees agreed that the employees would be responsible for the organisation and running of their weekly team meetings. Tom would attend the meetings when invited and would receive the memos of the meetings. This new team meeting practice was an innovation that enabled the employees to participate in the development of their work.

Altogether, there were 47 initiatives in which the employees expressed commitment to implementation. When they considered that an initiative supported the way of working or made the work more efficient, they were committed to implement it. These initiatives formed mainly short paths but also medium-long and long paths.

Most often, the reason why an initiative presented by an employee was not implemented was that Tom used his power not to make a decision. The following example from the short path describes an initiative that was not implemented. In an employee-led follow-up meeting on November 24 , 2011, Peter presented an initiative that would have simplified the work at the unit. He suggested that the production workers who took care of the sorting should put certain packages either into separate trolleys or on the top of all trolleys. This way the employees at the unit could start handling these packages immediately when they arrived.

Excerpt 4 (November 24, 2011, turns 477-482)

Peter: I would like to have the Nines [certain products]...

Susan: Separately.

Peter: Separately. It would simplify our life enormously.

Susan: Separate trolley. 
Peter: Because it ...

Tom: Yes, we can work towards that.

By saying that 'we can work towards that', Tom did not make any decision and did not commit to advancing the initiative. The implementation of the initiative would have required discussion and collaboration with the colleagues in the network.

Altogether, there were 22 initiatives that were not implemented due to the lack of a decision. In these cases Tom either deferred or did not promote the initiative, or the implementation was dependent on the decision of the management. The initiatives formed short, medium-long and long paths.

Resistance exercised by the employees was visible in the data as non-compliance. Our next example describes a potential innovation that was experimented with and developed over nine meetings, but that lost momentum at the end. In the CL session on December 10, 2010, the researcher proposed writing solution diaries. The idea was that the employees would describe difficult cases in writing and share tacit knowledge. This sharing of knowledge would enhance the efficiency of work and improve co-operation within the unit. Additionally, by sharing the solution diaries throughout the sorting centre and the network, the knowledge and respect for the work carried out in the work unit would increase.

During the CL, each employee wrote about either one or several difficult cases that they had taken care of, then presented these in the meetings. By discussing these cases the employees shared tacit knowledge. Ideas were developed about what format the diaries should be presented in, as well as how to distribute them. The employees proposed putting the diaries on bulletin boards in the rest rooms, drawing cartoon strips, and even recording a talking book. Tom suggested that they should publish cases in internal leaflets for personnel and that they could organise a competition for the production workers to solve a difficult case.

In the follow-up meeting, on September 23, 2011, the status of the solution diaries was discussed. The employees had not written any diaries since the spring of 2011 and they resisted continuing as they found it hard, so it was agreed to discontinue writing them.

Excerpt 5 (September 23, 2011, turns 698-704)

Peter: Someone who has a way with words can write them [solution diaries]. 
Researcher: Should we...

Peter: I personally don't... I find it is more work.

Kate: Work...

Laura: It is work. That's why it has remained undone.

Tom: It is documentation of work.

Peter: Exactly! If I may express my opinion, we will not continue.

With regard to 18 initiatives that were not implemented, the employees did not support or promote the initiative because they either believed it would not be effective or that the implementation would have required too much extra work. Initiatives that encountered resistance from bottom-up formed mainly short paths. However, there were also some initiatives that belonged to medium-long or long paths.

Resistance was visible in the actions of Tom and the employees, as well as the wider network. Tom tried to promote some initiatives but the actors in the neighbouring work unit failed to make any decisions. Thus power resided not only in the top-down and bottom-up forms of management, but also within in the wider network beyond the work unit.

\section{The sustainability of initiative and innovation implementation}

The researcher interviewed the participants in the CL during the summer and autumn of 2013. Major changes had taken place since the spring of 2012. The original group had consisted of eight employees and now there were ten workers. Moreover, the supervisor had changed. Despite the increase in the number of employees, human resources were insufficient to meet the demands of the increased amount of work. The employees faced the continuous challenge of efficiency in daily work. The work had become more monotonous. The idea of a multi-skilled employee, which had been regarded as important in the CL, had been set aside as it did not support an efficient performance of duties.

We will now turn to our fourth research question: to what extent are the initiatives and innovations sustainably implemented? Despite the major changes at work, the status concerning the implementation of initiatives and innovations had not altered much. The status in summer 2013 is shown in Table 5. Only two of the 61 implemented initiatives were no longer in use and one had changed. One initiative that had turned into an innovation but was no longer in use was the 
meetings chaired by the employees. The supervisor visited the employees daily and if someone made an initiative it was discussed in the open office. The initiative that also had turned into an innovation, but had changed, was the collection of indicators. It was no longer utilised by the employees in the development of the activity but followed only by the supervisor and the management.

Four of the initiatives that lost momentum or were left unimplemented during the follow-up had been changed or been implemented. The initiative that had lost momentum was related to the joint meetings with the neighbours. These were regarded as important, but now it was only the supervisor who participated in them and he communicated the ideas and decisions made to the employees. Three initiatives related to work activity that were not implemented during the follow-up had now been implemented. The one initiative that the management had presented and that was not implemented due to lack of resources had been put into practice.

\begin{tabular}{lrrrrrrr}
\hline & Implemented & $\begin{array}{c}\text { Lost } \\
\text { momentum }\end{array}$ & Terminated & $\begin{array}{c}\text { Implemented } \\
\text { once }\end{array}$ & Changed & Open & $\begin{array}{c}\text { Total } \\
(\%)\end{array}$ \\
\hline Employees & 35 & 6 & 12 & 0 & 1 & 6 & $60(57.1 \%)$ \\
Supervisor & 18 & 0 & 8 & 1 & 0 & 1 & $28(26.7 \%)$ \\
Management & 5 & 0 & 0 & 0 & 0 & 0 & $5(4.8 \%)$ \\
$\begin{array}{l}\text { Colleagues in } \\
\text { the wider }\end{array}$ & 1 & 0 & 0 & 0 & 0 & 1 & $2(1.9 \%)$ \\
network & & & & & & & \\
Researcher & 2 & 2 & 4 & 0 & 2 & 0 & $10(9.5 \%)$ \\
Total $(\%)$ & $61(58.1 \%)$ & $8(7.6 \%)$ & $24(22.9 \%)$ & $1(1 \%)$ & $3(2.9 \%)$ & $8(7.6 \%)$ & $105(100 \%)$ \\
\hline
\end{tabular}

Table 5. The status of the initiatives in 2013

During the interviews in summer 2013 the participants emphasised that the CL had enhanced cooperation between the employees. It had enabled the employees to raise problems, discuss different ways to develop activities and implement initiatives that improved them. During interviews conducted before the CL, one of the participants had mentioned that they had nine players in the group who played their own game on their own field. But now, in the summer of 2013, they played as a team on the same field.

\section{Discussion and conclusions}

In this study we have examined the production of initiatives by the employees at a work unit during a special CL intervention and longitudinal follow-up period. Over the years innovations research has highlighted the two ends of the innovations process - ideas generation and creativity, and ideas 
implementation. This study has focused on the path from initiatives to innovations. Our overall research question was: How are the initiatives turned into innovations, developed and implemented, or terminated? To answer this question, more specific questions were needed.

First, we examined whether the initiatives become paths, and if they do, what kind of profiles of initiative paths there are to be found. Our findings demonstrate, in line with Van de Ven and Poole (1990), that an initiative may follow different paths, along which the processing and outcomes, as well as the time needed for experimentation and testing, vary. On a short path, the future of an initiative was promptly decided. It was either accepted or abandoned. Reasons for a long initiative path were that the initiative was either discussed further on or it required experimentation and development. We argue that the creation of innovation paths demanded the transformative agency of the actors involved. As Engeström (2011) states, transformative agency involves the questioning of the status quo, searching for new possibilities, committing to change and implementing the generated initiatives. Although, ideas and suggestions were presented by individuals, collective action was needed to implement the initiative and accomplish a change.

Second, in the examination of innovation types and dynamic relationships among the initiatives, we discovered innovations on different levels. The majority of the initiatives and innovations were incremental changes aiming at improvements in work practices and modifications of tools used at work. However, by examining the connections between these initiatives and innovations, we found links - solution initiatives were linked to each other and hence contributed to process development. Thus, process development was not abstracted too far from the everyday work. According to Engeström (1995), in a system-level innovation the principles of the activity of an organisation are questioned and a new model is built by the actors. We discovered that by implementing the solution and process initiatives the employees, together with the supervisor Tom built qualitative changes at the system level, using small developmental steps.

Von Hippel and Tyre (1995) state that besides a particular product embodiment innovation can be seen as a continuous process. In our study there were five clearly defined solution innovations. However, innovation as a process was visible in the developmental activity of the members of the work unit. By initiating ideas to develop the current ways of working the employees sustained innovation activity from bottom-up.

Third, we examined which factors either contribute to, or prevent the implementation of, an initiative. Implementation is the critical phase in the innovation process and path creation (Klein and Knight, 2005). Our study focused particularly on the role of power relations in initiatives and 
innovations initiation. The system of power relations is comprised of power and resistance (Hardy and Clegg, 1996), which can be expressed from top-down and bottom-up. The supervisor expressed transformative agency by using directive power as a representative of the management, but also in enabling the employees to develop work activities. The employees, in turn, expressed commitment by innovating and implementing initiatives. However, both the supervisor and the employees took steps backwards, expressing resistance to some initiatives by not making any decisions or not implementing initiatives. The interplay between the parties was as though it was a dance of transformative agency in the field of power relations. Pickering (2010) has described a dance of agency between an individual and an artifact, but in our study there was a collective dance between all the actors involved.

The CL method has been implemented in several intervention studies in work organisations ranging from hospitals and libraries to factories (Sannino et al., 2016; Sannino and Engeström, 2017). We showed that, as within those interventions, the CL intervention offered the employees the opportunity to initiate ideas, to experiment with initiatives, and to develop solutions to work-related problems as part of their work. After the CL, the employees continued developing their work activity in employee-led team meetings. Our fourth research question focused on the sustainability of the implemented initiatives and innovations. We discovered that ideas that are developed by the employees themselves to support and enhance work activity are sustainable in a changing environment. The active role of the supervisor in enabling and supporting the innovation process is needed to involve all the members in development work.

Based on our findings, we suggest that focusing on clusters of initiatives instead of individual innovations, and seeing innovation as a process rather than a clear product embodiment, offer new viewpoints to research on employee-driven innovations. Furthermore, a longitudinal approach is required to identify the development of initiatives, because incremental solution- and processinitiatives and innovations can change the whole activity system of the actors involved. By examining the initiative paths and power relations the sustainability of generated initiatives and factors influencing the implementation can be revealed. 


\section{References}

Amabile, T.M. (1996), Creativity in context, Westview Press, Boulder, CO.

Arthur, W. B. (1989), "Competing technologies, increasing returns, and lock-in by historical events", Economic Journal, Vol. 99, pp. 116-131.

Blackler, F., Crump, N. and McDonald, S. (1999), "Managing experts and competing through innovation: An activity theoretical analysis”, Organization, Vol. 6 No. 1, pp. 5-31.

Blackler, F. and McDonald, S. (2000), "Power, mastery and organizational learning”, Journal of Management Studies, Vol. 37 No. 6, pp. 833-851.

Baer, M. and Frese, M. (2003), "Innovation is not enough: climates for initiative and psychological safety, process innovations, and firm performance", Journal of Organizational Behavior, Vol. 24, pp. 45-68.

Buech, V.I.D., Michel, A. and Sonntag, K. (2010), "Suggestion systems in organizations: what motivates employees to submit suggestions?", European Journal of Innovation Management, Vol. 13 No. 4, pp. 507-525.

David, P. A. (1985), “Clio and the economics of QWERTY”, American Economic Review, Vol. 75, pp. 332-337.

De Jong, J.P.J. and Den Hartog, D.N. (2007), “How leaders influence employees’ innovative behavior", European Journal of Innovation Management, Vol. 10 No. 1, pp. 41-64.

Ellström, P-E. (2010), "Practice-based innovation: a learning perspective", Journal of Workplace Learning, Vol. 22 No. 1/2, pp. 27-40.

Engeström, Y. (1995), "Innovative organizational learning in medical and legal settings”, in Martin, L.M.W., Nelson, K. and Tobach, E. (Eds), Sociocultural psychology, Theory and practice of doing and knowing, Cambridge University Press, Cambridge, pp. 326-356.

Engeström, Y. (2007), "Putting Vygotsky to work: The change laboratory as an application of double stimulation", in Daniels, H., Cole, M. and Wertsch, J.V. (Eds), The Cambridge companion to Vygotsky, Cambridge University Press, Cambridge, pp. 363-382.

Engeström, Y. (2011), "From design experiments to formative interventions", Theory \& Psychology, Vol. 21 No. 5, pp. 598-628. 
Fenwick, T. (2003), “Innovation: examining workplace learning in new enterprises”, Journal of Workplace Learning, Vol. 15 No. 3, pp. 123-132.

Garcia, R. and Calantone, R. (2002), “A critical look at technological innovation typology and innovativeness terminology: a literature review", Journal of Product Innovation Management, Vol. 19, pp. 110-132.

Garud, R. and Karnoe, P. (2001), "Path creation as a process of mindful deviation", in Garud, R. and Karnoe, P. (Eds), Path Dependence and Creation, Erlbaum, Mahwah, NJ.

Garud, R. and Karnoe, P. (2003), "Bricolage vs. breakthrough: distributed and embedded agency in technology entrepreneurship", Research Policy, Vol. 32, pp. 277-300.

Gruber, M. (2010), "Exploring the origins of organizational paths: Empirical evidence from newly founded firms", Journal of Management, Vol. 36 No. 5, pp. 1143-1167.

Haapasaari, A., Engeström, Y. and Kerosuo, H. (2016), “Emergence of learners' transformative agency in a Change Laboratory intervention", Journal of Education and Work, Vol. 29, pp 232-262.

Hardy, C. (1996), "Understanding power: Bringing about strategic change”, British Journal of Management, Vol. 7 No. 1, pp. S3-16.

Hardy, C. and Clegg, S.R. (1996), "Some dare call it power", in Hardy, C., Clegg, S.R. and Nord, W.R. (Eds), Handbook of Organization Studies, Sage, London, pp. 622-641.

Holman, D., Totterdell, P., Axtell, C., Stride, C., Port, R., Svensson, R. and Zibarras, L. (2012), "Job design and the employee innovation process: The mediating role of learning strategies", Journal of Business and Psychology, Vol. 27, pp. 177-191.

Høyrup, S. (2010), "Employee-driven innovation and workplace learning: basic concepts, approaches and themes", Transfer, Vol. 16 No. 2, pp. 143-154.

Kesting, P. and Ulhøi, J.P. (2010), "Employee-driven innovation: extending the license to foster innovation", Management Decision, Vol. 48 No. 1, pp. 65-84.

Klein, J.K. and Knight, A.P. (2005), "Innovation implementation: overcoming the challenge”, Current Directions in Psychological Science, Vol. 14 No. 5, pp. 243-246.

Klein, J.K. and Sorra, J.S. (1996), "The challenge of innovation implementation”, Academy of Management Review, Vol. 21 No. 4, pp. 1055-1080. 
LePine, J.A. and Van Dyne, L. (1998), “Predicting voice behavior in work groups", Journal of Applied Psychology, Vol. 83, pp. 853-868.

Meeus, M.T.H. and Edquist, C. (2006), "Introduction" in Hage, J., Meeus, M.T.H. and Edquist, C. (Eds), Innovation, science and institutional change, Oxford University Press, Oxford, pp. 23-38.

Michaelis, B., Stegmaier, R. and Sonntag, K. (2009), "Shedding light on followers' innovation implementation behaviour: the role of transformational leadership, commitment to change, and climate for initiative", Journal of Managerial Psychology, Vol. 25 No. 4, pp. 408-429.

Mumford, M.D. (2000), "Managing creative people: Strategies and tactics for innovation", Human Resource Management Review, Vol. 10 No. 3, pp. 313-351.

Nonaka, I. (1994), “A dynamic theory of organizational knowledge creation”, Organization Science, Vol. 5 No. 1, pp. 14-37.

Ohly, S., Sonnentag, S. and Pluntke, F. (2006), "Routinization, work characteristics and their relationships with creative and proactive behaviors”, Journal of Organizational Behavior, Vol. 27 No. 3, pp. 257-279.

Orr, J. (1996), Talking about machines: an ethnography of a modern job, ILR Press, Ithaca, NY. Pickering, A. (2010), "Material culture and the dance of agency", in Hicks, D. and Beaudry, M. C. (Eds), The Oxford handbook of material culture studies, Oxford University Press, Oxford.

Rank, J., Pace, V.L. and Frese, M. (2004), “Three avenues for future research on creativity, innovation, and initiative", Applied Psychology: An International Review, Vol. 53 No. 4, pp. $518-528$.

Sannino, A. and Engeström, Y. (2017), "Co-generation of societally impactful knowledge in Change Laboratories", Management Learning, Vol. 48 No. 1, pp. 80-96.

Sannino, A., Engeström, Y. and Lemos, M. (2016), "Formative interventions for expansive learning and transformative agency", Journal of the Learning Sciences, Vol. 25 No. 4, pp. 599-633.

Shapiro, G. (2000), “Employee involvement: opening the diversity Pandora's Box?”, Personnel Review, Vol. 29 No. 3, pp. 304-323.

Schreyögg, G. and Sydow, J. (2011), “Organizational path dependence: A process view”, Organization Studies, Vol. 32 No. 3, pp. 321-335. 
Stack, M. and Gartland, M.P. (2003), "Path creation, path dependency, and alternative theories of the firm", Journal of Economic Issues, Vol. 37 No. 2, pp. 487-494.

Swan, J. and Scarbrough, H. (2005), “The politics of networked innovation", Human Relations, Vol. 58 No. 7, pp.913-943.

Thrane, S., Blaabjerg, S. and Moller, R.H. (2010), "Innovative path dependence: making sense of product and service innovation in path dependent innovation processes", Research Policy, Vol. 39, pp. 932-944.

Van de Ven, A. and Poole, M.S. (1990), "Methods for studying innovation development in the Minnesota innovation research program", Organization Science, Vol. 1 No. 3, pp. 313-335.

Van Driel, H. and Dolfsma, W. (2009), "Path dependence, initial conditions, and routines in organizations", Journal of Organizational Change Management, Vol. 22 No. 1, pp. 49-72.

West, M.A. and Farr, J.L. (1990), Innovation and Creativity at Work: Psychological and Organizational Strategies, Wiley, Chichester.

Virkkunen, J. (2006), "Dilemmas in building shared transformative agency”, Activités, Vol. 3 No. 1, pp. 43-66.

Virkkunen, J. and Newnham, D.S. (2013), The Change Laboratory. A tool for collaborative development of work and education, Sense Publishers, Rotterdam.

Von Hippel, E. and Tyre, M.J. (1995), "How learning by doing is done: problem identification in novel process equipment", Research Policy, Vol. 24, pp. 1-12.

Vänninen, I., Pereira-Querol, P. and Engeström, Y. (2015), “Generating transformative agency among horticultural producers: An activity-theoretical approach to transforming Integrated Pest Management”, Agricultural Systems, Vol. 139, pp. 38-49. 